\title{
Совершенствование системы питания при выращивании отечественных гибридов капусты белокочанной
}

\author{
Improving the nutrition system in the cultivation of domestic hybrids of white cabbage
}

\section{Вирченко И.И., Костенко Г.А.}

\section{Аннотация}

Агрохолдинг «Поиск» предлагает отечественным овощеводам гибриды капусты белокочанной, позволяющие организовать конвейер производства овощной продукции. Одновременно с этим на базе ВНИИО - филиала ФГБНУ ФНЦО и ЗАО «Куликово» идет разработка и совершенствование технологий их выращивания. В 2019 году овощеводам предложена технология выращивания ряда гибридов на примере ЗАО «Куликово», позволяющая получать урожай на уровне лучших зарубежных аналогов. В статье представлены результаты испытания отечественных гибридов в Московской области на базе ВНИИО - филиала ФГБНУ ФНЦО на различных фонах минерального питания: контроль без удобрений, $\mathrm{N}_{120} \mathrm{P}_{120} \mathrm{~K}_{180}, \mathrm{~N}_{180} \mathrm{P}_{180} \mathrm{~K}_{270}$. Почва опытного участка относится к типу аллювиальных луговых насыщенных почв: среднесуглинистая, окультуренная. Погодные условия в годы проведения исследований были не совсем благоприятны для роста и развития капусты белокочанной, особенно 2018 год, характеризующийся жарким летом и небольшим количеством осадков. Дефицит влаги компенсировали дополнительными поливами. В 2015-2019 годах изучены следующие гибриды: $F_{1}$ Княгиня, $F_{1}$ Герцогиня, $F_{1}$ Континент (селекции Агрохолдинга «Поиск»), $F_{1}$ Идиллия, $F_{1}$ Дмитровский (совместные селекционные достижения ФГБНУ ФНЦО и Агрохолдинга «Поиск»), $\mathrm{F}_{1}$ Флагман (cелекции Агрохолдинга «Поиск» и ООО «Селекционная станция им. Н.H. Тимофеева»), F Бомонд Агро (гибрид Агрохолдинга «Поиск», ФГБНУ ФНЦО и ООО «Селекционная станция имени Н.Н. Тимофеева»). Урожайность товарной продукции на фоне без удобрений варьировала от 53 до 57,3 т/га, максимальная урожайность отмечена у гибрида $F_{1}$ Бомонд Агро - 57,3 т/га. Такую урожайность гибриды обеспечивают за счет своего генетического потенциала. При внесении удобрений в дозе $\mathrm{N}_{120} \mathrm{P}_{120} \mathrm{~K}_{180}$ урожайность товарной продукции варьировала от 61,6 до 76,8 т/га, прибавка урожая составила 16,23-35,21\%. Максимальное значение отмечено у гибрида $F_{1}$ Герцогиня - 76,8 т/га. При увеличении нормы полного минерального удобрения до $\mathrm{N}_{180} \mathrm{P}_{180} \mathrm{~K}_{270}$ наибольшей урожайностью товарной продукции обладают гибриды $F_{1}$ Идиллия и $F_{1}$ Герцогиня - 89,3 т/га и 84,9 т/га соответственно. Гибрид $F_{1}$ Континент в 2019 году имел наибольшую урожайность среди гибридов - 91,2 т/га, прибавка за счет внесения удобрений составила 70,79\%. Высокая урожайность объясняется высокой морфологической выравненностью, сильной корневой системой и высокой стандартностью продукции - 100\% по всем вариантам опыта.

Ключевые слова: капуста белокочанная, гибрид, удобрения, норма удобрений, урожайность, прибавка урожайности.

Для цитирования: Вирченко И.И., Костенко Г.А. Совершенствование системы питания при выращивании отечественных гибридов капусты белокочанной // Картофель и овощи. 2020. №1. C. 9-11. https://doi.org/10.25630/PAV.2020.25.71.005
Virchenko I.I., Kostenko G.A.

\section{Abstract}

Poisk Agro Holding offers domestic vegetable growers hybrids of white cabbage, allowing to organize a conveyor for the production of vegetable products. At the same time, there is a development and improvement of technologies for their growing on the basis of ARRIVG - branch of FSBSI FSCVG and close corporation Kulikovo. The technology for growing a number of hybrids was proposed to vegetable growers in 2019 using the example of close corporation Kulikovo, which allows you to get a crop at the level of the best foreign analogues. The results are presented in this article on the testing of domestic hybrids in the Moscow region on the basis of ARRIVG - branch of FSBSI FSCVG on various backgrounds of mineral nutrition: control without fertilizers, $\mathrm{N}_{120} \mathrm{P}_{120} \mathrm{~K}_{180}, \mathrm{~N}_{180} \mathrm{P}_{180} \mathrm{~K}_{270}$. The soil of the experimental plot is alluvial meadow saturated soils: medium loamy, cultivated. Weather conditions during the years of research were not entirely favorable for the growth and development of white cabbage, especially in 2018, which is characterized by hot summers and low rainfall. The moisture deficit was compensated by additional watering. In 2015-2019, the following hybrids were studied: $F_{1}$ Knyaginya, $F_{1}$ Gertsoginya, $F_{1}$ Kontinent (selection of Poisk Agro Holding); $F_{1}$ Idillya, $F_{1}$ Dmitrovsky (joint selection achievements of the FSCVG and Poisk Agro Holding), $F_{1}$ Flagman (selection of Poisk Agro Holding and Breeding Station after N.N. Timofeev Ltd) $F_{1}$ Bomond Agro (a hybrid of Poisk Agro Holding, FSCVG and Breeding station after N.N. Timofeev Ltd). Productivity of marketable products varied against 53 to $57.3 \mathrm{t}$ /ha without fertilizers; the maximum yield was observed for the $F_{1}$ Bomond Agro hybrid $57.3 \mathrm{t} /$ ha. Hybrids provide this yield due to their genetic potential. Productivity of marketable products ranged from 61.6 to $76.8 \mathrm{t} / \mathrm{ha}$ when fertilizers were applied at a dose of $\mathrm{N}_{120} \mathrm{P}_{120} \mathrm{~K}_{180}$, yield increase was $16.23-35.21 \%$. The maximum value was observed for the $F_{1}$ Gertsoginya hybrid of $76.8 \mathrm{t} / \mathrm{ha}$. Hybrids of $F_{1}$ Idillya and $F_{1}$ Gertsoginya possess the highest yield of marketable products with an increase in the rate of full mineral fertilizer to $\mathrm{N}_{180} \mathrm{P}_{180} \mathrm{~K}_{270}$ $-89.3 t /$ ha and $84.9 t /$ ha, respectively. In 2019, the $F_{1}$ Kontinent hybrid had the maximum yield among hybrids of $-91.2 \mathrm{t} / \mathrm{ha}$, the increase due to the application of fertilizers was $70.79 \%$. High productivity is explained by high morphological uniformity, a strong root system and high standard production of $100 \%$ for all variants of experience.

Key words: white cabbage, hybrid, fertilizers, fertilizer rate, yield, yield increase.

For citing: Virchenko I.I., Kostenko G.A. Improving the nutrition system in the cultivation of domestic hybrids of white cabbage. Potato and Vegetables. 2020. No1. Pp. 9-11 (In Russ.). https://doi. org/10.25630/PAV.2020.25.71.005 настоящее время в Государственном Реестре селекционных достижений, допущенных к использованию на территории Российской Федерации, находится
439 сортов и гибридов капусты белокочанной [1]. Ежегодно научные организации и селекционно-семеноводческие фирмы выводят новые гибриды для товарного овощеводства, от- вечающие требованиям рынка, совмещающие в себе высокую урожайность, товарность, устойчивость к болезням во время вегетации и в период хранения продукции. Максимально реали- 


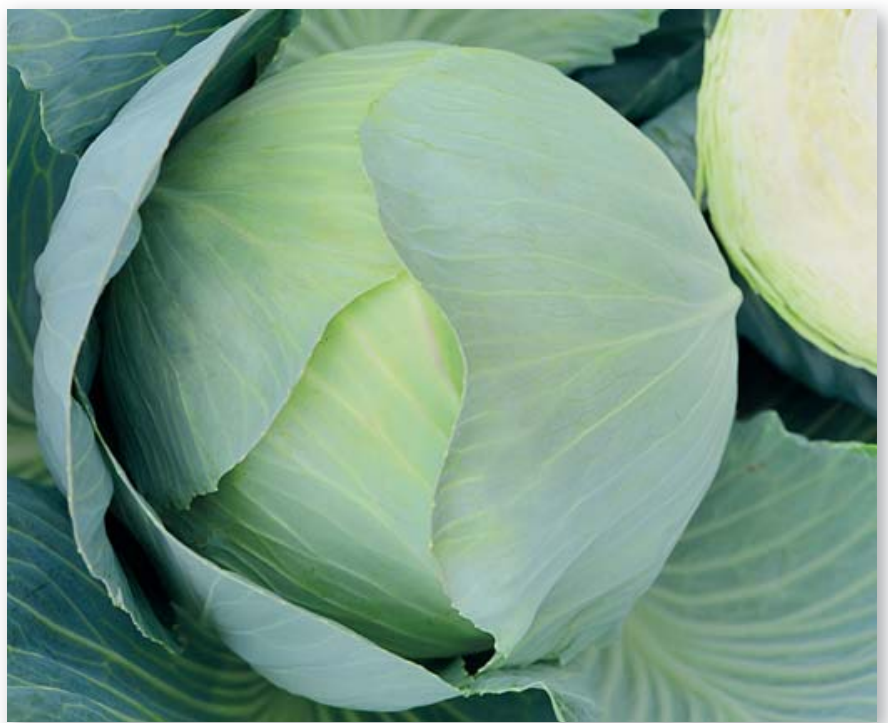

Гибрид $F_{1}$ Идиллия

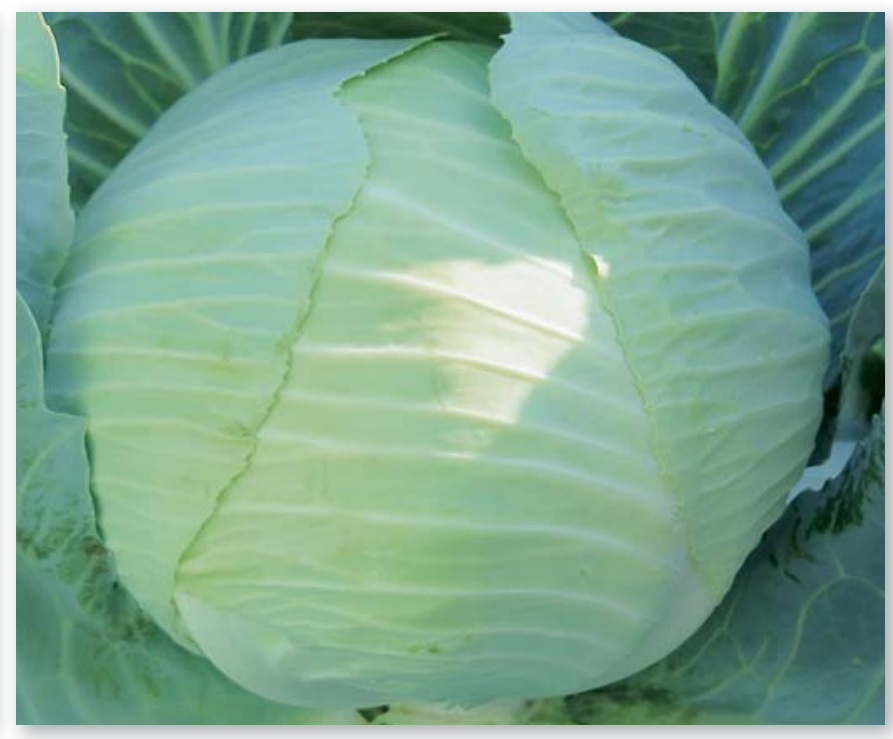

Гибрид $F_{1}$ Герцогиня зовать потенциал отечественных гибридов можно только на современных индустриальных технологиях выращивания. Такие подходы используются в ЗАО «Куликово», на их основе разработаны и в 2019 году изданы технологии выращивания для ряда отечественных гибридов, которые предлагает рынку Агрохолдинг «Поиск». Работа по совершенствованию технологий выращивания каждого гибрида продолжается, с учетом специфики условий разных регионов РФ. Важнейший элемент технологии для реализации полного потенциала урожайности каждого конкретного гибрида - система минерального питания. Разработка и совершенствование научно обоснованной системы удобрений - один из самых важных вопросов в с.- х. производстве, так как он определяет не только уровень урожайности культур, но и направление изменения повышения и сохранения плодородия почв в целом [2].
Условия, материалы и методы исследований

На протяжении 2015-2019 годов изучали коммерческие и новые перспективные гибриды от среднеспелого срока созревания до поздней группы на хранение. Цель исследований - определение отзывчивости гибридов капусты белокочанной на нормы удобрения по величине общей урожайности и выходу стандартной продукции. В качестве материала для исследований изучали гибриды: $F_{1}$ Княгиня, $F_{1}$ Герцогиня, $F_{1}$ Континент (селекции Агрохолдинга «Поиск»), $F_{1}$ Идиллия, $\mathrm{F}_{1}$ Дмитровский (совместные селекционные достижения ФГБНУ ФНЦО и Агрохолдинга «Поиск»), $F_{1}$ Флагман (селекции Агрохолдинга «Поиск» и ООО «Селекционная станция им. Н.Н. Тимофеева»), $F_{1}$ Бомонд Агро (гибрид Агрохолдинга «Поиск», ФГБНУ ФНЦО и ООО «Селекционная станция им. Н.Н. Тимофеева»).
Результаты испытания других гибридов были представлены более подробно ранее [3].

Посев семян - в кассеты № 64 с диаметром ячейки 4×417-18 апреля в пленочную теплицу, рассаду высаживали в 3 декаде мая по схеме 70×40. Отзывчивость гибридов на удобрения изучали на трех фонах: без удобрений, $\mathrm{N}_{120} \mathrm{P}_{120} \mathrm{~K}_{180}$, $\mathrm{N}_{180} \mathrm{P}_{180} \mathrm{~K}_{270}$. При выращивании образцов капусты агротехника была общепринятой, подготовку почвы и уход за растениями проводили механизированным способом. Урожай убирали 9-12 октября. Учет урожая проводили сплошным поделяночным способом. Опыты закладывали на базе ВНИИО - филиала ФГБНУ ФНЦО согласно «Методике опытного дела в овощеводстве» [4].

Почва опытного участка, где проводили исследования, относится к типу аллювиальных луговых насыщенных почв: среднесуглинис-

Влияние удобрений на урожайность капусты белокочанной, среднее за 2015-2019 годы

\begin{tabular}{|c|c|c|c|c|c|c|c|c|c|c|}
\hline \multirow{3}{*}{ Гибрид } & \multicolumn{3}{|c|}{ Контроль (без удобрений) } & \multicolumn{3}{|c|}{$\mathrm{NPK}_{\text {pac4. }}-\mathrm{N}_{120} \mathrm{P}_{120} \mathrm{~K}_{180}$} & \multicolumn{3}{|c|}{$1,5 \mathrm{NPK}-\mathrm{N}_{180} \mathrm{P}_{180} \mathrm{~K}_{270}$} & \multirow{3}{*}{$\begin{array}{l}\text { Группа } \\
\text { спелости }\end{array}$} \\
\hline & \multicolumn{2}{|c|}{ урожайность, т/га } & \multirow{2}{*}{$\underset{\%}{\text { стандарт, }}$} & \multicolumn{2}{|c|}{ урожайность, т/га } & \multirow{2}{*}{$\underset{\%}{\text { стандарт, }}$} & \multicolumn{2}{|c|}{ урожайность, т/га } & \multirow{2}{*}{$\begin{array}{c}\text { стандарт, } \\
\%\end{array}$} & \\
\hline & общая & стандарт & & общая & стандарт & & общая & стандарт & & \\
\hline $\mathrm{F}_{1}$ Флагман & 59,1 & 53,1 & 89,76 & 71,3 & 65,3 & 91,65 & 77,2 & 72,3 & 93,65 & \multirow{2}{*}{ среднеспелая } \\
\hline $\mathrm{F}_{1}$ Княгиня & 58,8 & 53,0 & 90,05 & 67,0 & 61,6 & 91,94 & 72,8 & 69,0 & 94,71 & \\
\hline $\mathrm{F}_{1}$ Бомонд Агро & 61,6 & 57,3 & 93,13 & 75,2 & 72,7 & 96,71 & 84,1 & 82,5 & 98,04 & \multirow{5}{*}{ позднеспелая } \\
\hline $\mathrm{F}_{1}$ Герцогиня & 59,5 & 56,8 & 95,51 & 77,9 & 76,8 & 98,63 & 85,7 & 84,9 & 99,07 & \\
\hline $\mathrm{F}_{1}$ Дмитровский & 61,2 & 55,0 & 90,00 & 69,3 & 66,4 & 95,95 & 77,0 & 75,1 & 97,50 & \\
\hline F & 55,1 & 55,1 & 100,00 & 73,5 & 72,8 & 99,05 & 89,3 & 89,3 & 100,00 & \\
\hline $\mathrm{F}_{1}$ Континент $^{\star}$ & 53,4 & 53,4 & 100,00 & 74,1 & 74,1 & 100,00 & 91,2 & 91,2 & 100,00 & \\
\hline
\end{tabular}


тая, окультуренная, влагоемкая, глубина пахотного слоя 27 см, глубина залегания грунтовых вод более $2 \mathrm{M}, \mathrm{pH}-5,5-6,1$, содержание гумуса 3,5-3,8\%, общего азота 0,19-0,24\%, нитратного азота 2-2,8 мг/100 г, содержание фосфора в почве 17,619,1 мг/100 г, обеспеченность калием 7-8,2 мг/100 г. Погодные условия в годы проведения исследований были не совсем благоприятны для роста и развития капусты белокочанной: 2016 год отмечен как жаркий влажный год; весна 2017 года была прохладная, лето теплое, август и сентябрь - жаркими; 2018 год характеризовался жарким летом и небольшим количеством осадков; в 2019 году июнь, август и сентябрь были наиболее засушливыми. Дефицит влаги компенсировали дополнительными поливами.

\section{Результаты исследований}

Урожайность товарной продукции на фоне без удобрений варьировала от 53 до 57,3 т/га, максимальная урожайность отмечена у гибрида $F_{1}$ Бомонд Агро 57,3 т/га (табл.). У гибрида $F_{1}$ Герцогиня урожайность была чуть меньше 56,8 т/га, он отличался высокой стандартностью кочанов. Гибриды, выращенные на фоне без удобрений, дают урожай продукции за счет своего генетического потенциала. При внесении удобрений в дозе $\mathrm{N}_{120} \mathrm{P}_{120} \mathrm{~K}_{180}$ урожайность товарной продукции варьировала от 61,6 до 76,8 т/га, прибавка урожая составила 16,23-35,21\%. Максимальное значение отмече- но у гибрида $F_{1}$ Герцогиня 76,8 т/га. Прибавка урожая составила 35,21\%. Гибрид $\mathrm{F}_{1}$ Континент оказался более отзывчив из гибридов на такую норму удобрений, прибавка урожая составила $38,7 \%$.

Максимальные прибавки урожая 36,1-70,7\% относительно фона без удобрений отмечены при увеличении нормы полного удобрения до $\mathrm{N}_{180} \mathrm{P}_{180} \mathrm{~K}_{270}$. Наибольшей урожайностью товарной продукции на протяжении 2015-2019 годов обладал гибрид $F_{1}$ Идиллия - 89,3 т/га. Гибрид оказался отзывчив на такую норму удобрений и дал прибавку урожая 62,07\% по товарной продукции. Гибрид $F_{1}$ Герцогиня имел урожайность 84,9 т/га (прибавка урожая за счет повышенной дозы удобрений 49,47\%), обладал высокой адаптивностью и морфологической выравненностью. Перечисленные гибриды идеально подходят для крупных сельхозпроизводителей, использующих высокий уровень агротехники, более того, гибрид $\mathrm{F}_{1}$ Герцогиня - один из лучших проверенных и зарекомендовавших себя гибридов капусты белокочанной селекции Агрохолдинга «Поиск» и реальный пример импортозамещения в РФ [5].

Гибрид $\mathrm{F}_{1}$ Континент испытывался только в 2019 году, однако по результатам можно отметить максимальную урожайность 91,2 т/га. Прибавка урожайности за счет внесения удобрений - 70,79\%. Гибрид $F_{1}$ Континент давал большой урожай за счет высокой морфологической выравненнос- ти, сильной корневой системы и высокой стандартности продукции, доля которой достигала 100\% по всем вариантам опыта. Стоит отметить, что норма удобрений $\mathrm{N}_{180} \mathrm{P}_{180} \mathrm{~K}_{270}$ положительно влияла на стандартность продукции и увеличивала показатель по изученным гибридам на 4-8\%.

Показатель содержания сухого вещества у гибридов варьировал в пределах 7,7-12,6\%, суммы сахаров $3,11-5,54 \%$, витамина С - 20,529,1 мг\%. Максимальное содержание сухого вещества отмечено у гибрида $F_{1}$ Герцогиня - 12,6\%. Повышенное содержание витамина С отмечено в кочанах гибридов $F_{1}$ Идиллия и $F_{1}$ Герцогиня - 29,1 и 28,5 мг/100 г соответственно. Согласно действующим в настоящее время установленным нормам ПДК нитратов в поздней белокочанной капусте [6] по изучаемым вариантам содержание NO3 в продукции составило 156-416 мг/кг и не превышало установленных норм ПДК нитратов в поздней капусте.

\section{Выводы}

Таким образом, наибольшие прибавки урожая 36,1-70,7\% отмечены при увеличении нормы полного удобрения до $\mathrm{N}_{180} \mathrm{P}_{180} \mathrm{~K}_{270}$. Наибольшей отзывчивостью на удобрения обладали гибриды $\mathrm{F}_{1}$ Идиллия и $\mathrm{F}_{1}$ Герцогиня, прибавка товарной урожайности этих гибридов составила $62,07 \%$ и 49,47\% соответственно.

\section{Библиографический список}

1.Государственный реестр селекционных достижений, допущенных к использованию. Т.1. «Сорта растений». М.: ФГБНУ «Росинформагротех», 2019. 516 с.

2.Церлинг В.В. Агрохимические основы диагностики минерального питания сельскохозяйственных культур. М., 1978. 216 с.

3.Вирченко И.И., Костенко Г.А., Габдулин А.Г. Система удобрений для новых гибридов капусты // Картофель и овощи. 2018. №7. С. $19-20$

4.Литвинов С.С. Методика полевого опыта в овощеводстве. М.: Россельхозакадемия, 2011. 648 с.

5.Костенко Г.А. Гибрид F1 Герцогиня - реальный пример импортозамещения // Картофель и овощи. 2019. №2. С. 39-40.

6.Нормы ПДК нитратов [Электронный ресурc] URL: https:// www.ecomerka.ru/nitrates.php\#n6. Дата обращения: 05.11.19.

\section{References}

1.The state register of selection achievements allowed for use. T.1. Plant Varieties. M.: FSINI Rosinformagroteh, 2019. 516 p. (In Russ). 2.Tserling V.V. Agrochemical basis for the diagnosis of mineral nutrition of agricultural crops. M., 1978. 216 p. (In Russ).

3.Virchenko I.I., Kostenko G.A., Gabdulin A.G. Fertilizer system for new cabbage hybrids // Potato and vegetables. 2018. No. 7. Pp.1920 (In Russ).

4.Litvinov S.S. Methods of field experience in vegetable growing. M.: Russian Agricultural Academy, 2011. 648 p. (In Russ).

5.Kostenko G.A. Hybrid F1 Gertsoginya - a real example of import substitution // Potato and vegetables. 2019. №2. Pp. 39-40 (In Russ).

6.Norms of maximum concentration limit for nitrates [Web resource] URL: https://www.ecomerka.ru/nitrates.php\#n6. Date of access: 05.11.19 (In Russ).

\section{Об авторах}

Вирченко Иван Иванович, канд. с-х. наук, с.н.с. лаборатории хранения, ВНИИО - филиал ФГБНУ «Федеральный научный центр овощеводства» (ВНИИО - филиал ФГБНУ ФНЦО). E-mail: vniioh@yandex.ru

Костенко Галина Александровна, канд. С-х. наук, в.н.с. лаборатории селекции капустных культур, ВНИИО - филиал ФГБНУ ФНЦО, селекционер Агрохолдинга «Поиск». E-mail: kostenko@poiskseeds.ru

\section{Author details}

Virchenko I.I., Cand. Sci. (Agr.), senior research fellow of the storage laboratory, ARRIVG - branch of the Federal State Budgeteri Scientific Institution of Federal Scientific Vegetable Center (ARRIVG - branch of FSBSI FSCVG). E-mail: vniioh@yandex.ru

Kostenko G.A., Cand. Sci. (Agr.), leading research fellow of cabbage breeding laboratory, ARRIVG - branch of FSBSI FSCVG, breeder of the Poisk Agro Holding. E-mail: kostenko@poiskseeds.ru 